\title{
Properties of Poly(vinyl chloride) Modified by Cellulose
}

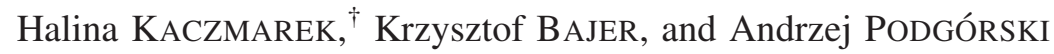 \\ Faculty of Chemistry, Nicolaus Copernicus University, Gagarin 7, 87-100 Torun, Poland
}

(Received July 30, 2004; Accepted February 9, 2005; Published May 15, 2005)

\begin{abstract}
Compositions of poly(vinyl chloride) with 2-10 (w/w) cellulose were prepared by extrusion. The mechanical properties and water absorptiveness of modified PVC have been measured. For the purpose of estimating the susceptibility to microorganisms' attack, all samples were being composted in garden soil for up to 14 months. Microbial analysis of soil used has been made.

The biodegradation efficiency was estimated in terms and by means of weight loss, ATR-FT IR spectroscopy, as well as changes in mechanical resistance. Moreover, thermal stability of virgin and composted samples was studied by thermogravimetry.

It has been found that the addition of a small amount of cellulose to PVC changes only slightly its properties. Intermolecular interactions and also some thermal crosslinking taking place during the processing of samples' preparation retard the biodegradation of PVC + cellulose blends. [DOI 10.1295/polymj.37.340]

KEY WORDS Poly(vinyl chloride) / Cellulose / Blend Properties / Biodegradation / Thermal Stability /
\end{abstract}

Polymeric materials have considerably influenced and enhanced the development of numerous branches of industry owing to their various and diverse properties which can be additionally modified in a wide range aimed at meeting the commercial and utility requirements. Plastics very often substitute and replace other raw materials such as glass, metals and paper.

From ecological point of view, the disadvantage of synthetic plastics is their non-degradability in natural environment. Mixing of synthetic polymers with appropriate natural biopolymers may lead to obtaining biodegradable compositions. In the last decade, such blends have attracted much attention and interest because their production at a larger scale may lead to an essential reduction of waste in landfills. However, usually only the biopolymer undergoes decomposition activated by microorganisms, whereas the synthetic component only becomes disintegrated into small pieces and dissipated. ${ }^{1-6}$

Biodegradation studies are usually conducted in laboratory conditions, ${ }^{7-9}$ which can differ significantly from the processes occurring in natural environment. The composting process depends on many factors such as temperature, humidity, $\mathrm{pH}$, presence of oxygen, amount and types of bacteria and fungi. The chemical structure (presence or lack of functional groups with oxygen or nitrogen atoms, crosslinking sites) and physical state (crystallinity, porosity) of polymeric materials strongly effect their biodegradability.

The aim of present work was to study the properties of poly(vinyl chloride) (PVC) modified by small amounts $(2-10 \mathrm{w} / \mathrm{w})$ of cellulose, and to check the susceptibility of samples to biodegradation. According to the published data, ${ }^{10}$ even a low content of natural component in polymeric composition can induce and facilitate its biodegradation.

Cellulose is a plentiful and easily available natural polysaccharide, which is synthesized in green plants (under solar radiation) and also by some bacteria (e.g., Bacillus xylinum).

PVC is one of the most popular and cheapest synthetic polymers that has been produced at a large scale for many years. The mixing of both mentioned polymers may prove to be an economic and environmentally-friendly solution for plastic packaging, however, there is a need for carrying out detailed investigations of the blends' properties as well as the influence of degradation and decomposition products on the natural environment. It was also interesting to investigate and get knowledge on how the used small amounts of cellulose affect and change the utility properties of PVC such as mechanical characteristics, water absorptiveness and thermal resistance. These properties are of great interest and importance from the viewpoint of practical application of new materials.

\section{EXPERIMENTAL}

\section{Materials}

Commercial suspension PVC (PVC-S, $K=61.8$ ) produced by Anvil S.A., Włocławek, Poland, and cellulose powder (Sigma) were used as the main components for blend preparation. The additives necessary

${ }^{\dagger}$ To whom correspondence should be addressed (E-mail: halina@chem.uni.toru.pl). 
Table I. Composition of PVC samples

\begin{tabular}{lc}
\hline Component & Weight parts \\
\hline PVC-S & 100 \\
CP-51 & 1.5 \\
ES & 5.0 \\
Aminosilan & 1.0 \\
WP-1 & 0.5 \\
\hline
\end{tabular}

for samples' extrusion were: calcium-zinc thermal stabilizer Ergoterm CP-51 and epoxidized soya oil Ergoterm ES, which is also a plasticizer (Boryszew S.A., Poland), polyethylene wax WP-1 (Poli-Chem Blachownia sp. z o.o.), and aminosilane: $\mathrm{H}_{2} \mathrm{~N}\left(\mathrm{CH}_{2}\right)_{3}$ $\mathrm{Si}\left(\mathrm{OCH}_{3}\right)_{3}$ (Aldrich) as compatibilizer. The composition of prepared blends is shown in Table I.

The PVC blends contained 2-10 weight parts of added cellulose. Such dry blends of PVC and cellulose with appropriate additives were mixed and extruded using the Plasti-Corder PLV-151 extruder (Brabender) with a sheet die at $170{ }^{\circ} \mathrm{C}$ and speed of $60 \mathrm{rpm}$. Nontransparent films of about $0.6-0.7 \mathrm{~mm}$ thickness were obtained.

The blends of PVC + cellulose were always compared to reference specimen, which was PVC containing the same amount of stabilizer, plasticiser and compatibiliser (composition given in Table I).

\section{Analysis}

The mechanical properties were measured using Instron tensile testing machine, Model 1026, modernized by its connection to computer. The standard dumbbell samples were used. ${ }^{11}$ The speed of crosshead was $5 \mathrm{~mm} / \mathrm{min}$. The average ultimate tensile strength $(\sigma, \mathrm{MPa})$ was calculated by dividing the force applied $(F)$ by the cross-sectional area $(A): \sigma=F / A$. Elongation at break $(\varepsilon, \%)$ was calculated as a ratio of change in the sample length versus the starting length $(l): \varepsilon=\Delta l / l$. The tensile modulus $(E)$, which is the ratio: $E=\sigma / \varepsilon$ was calculated for the initial stage of tensile experiment, always at the same elongation $(\varepsilon=3 \%)$, at which the Hook's law is still fulfilled, i.e., the $\sigma=f(\varepsilon)$ function is a straight line.

All the mechanical parameters were calculated basing on six measurements made for samples of the same type. As the found differences of $\sigma$ and $\varepsilon$ absolute values were small, the relative percentage changes of these parameters were calculated following the formulas:

$$
\begin{aligned}
\Delta \sigma(\%) & =\frac{\sigma_{\mathrm{t}}-\sigma_{0}}{\sigma_{0}} 100 \% \\
\Delta l(\%) & =\frac{\Delta l_{\mathrm{t}}-\Delta l_{0}}{\Delta l_{0}} 100 \%
\end{aligned}
$$

where $\sigma_{\mathrm{t}}, \sigma_{0}$ are ultimate strength values for samples composted and before composting ( $t$ - time of biodegradation in months), and $\Delta l_{\mathrm{t}}, \Delta l_{0}$ are elongations at break for samples composted and before composting, respectively.

The changes of water absorptiveness (WA) were tested according to the applicable Polish Standard. ${ }^{12}$ Dry samples (weight of $0.3-0.4 \mathrm{~g}$ ) were placed in boiling distilled water for $30 \mathrm{~min}$, cooled to room temperature (in water), then dried up rapidly with blottingpaper, and weighted.

The theromogravimetric analysis was carried out at a heating rate of $5{ }^{\circ} \mathrm{C} / \mathrm{min}$ from room temperature up to $600^{\circ} \mathrm{C}$ using TA Instrument SDT 2920 Simultaneous DSC-TGA. All samples (weight of 4-6 mg) were placed in aluminum pans. The TG, DTG and DTA curves were recorded under nitrogen atmosphere. The values of: $T_{0}\left({ }^{\circ} \mathrm{C}\right)$ - on-set degradation temperature; $T_{\max }\left({ }^{\circ} \mathrm{C}\right)$-maximum degradation rate temperature; $\Delta m_{1}$-amount of solid residue at maximum degradation rate, and $\Delta m_{2}$ - amount of solid residue at the end of process at $550{ }^{\circ} \mathrm{C}$-were obtained from the thermograms. The way of estimating the above parameters is shown in Figure 1.

\section{Composting}

Samples of the same form as those used for mechanical properties (dumbbell, length $50 \mathrm{~mm}$, width of neck $4 \mathrm{~mm}$, thickness $0.6-0.7 \mathrm{~mm}$ ) were placed in the garden soil and composted at room temperature in laboratory conditions for the time up to 14 months. The humidity was $20-40 \%$ and $\mathrm{pH}$ 7.5-8.2. Periodically, the composites were taken off from soil for analysis. Before the tests, samples were washed with distilled water and then dried at a vacuum drier.

The progress of biodegradation was monitored in terms of weight loss and tested by means of FT IR spectroscopy using Genesis II FT IR spectrophotometer (Mattson, USA) with ATR device (MIRacle ${ }^{\mathrm{TM}}$ PIKE Technologies with ZnSe crystal, for which the angle between incident beam and line perpendicular to sample surface was $45^{\circ}$ ).

\section{Characteristics of Garden Soil ${ }^{13-15}$}

The total number of bacteria on soil extract agar was counted and estimated as $2.5 \times 10^{7} \mathrm{cfu}$ (colony forming units) per gram of soil dry weight (the enzymes of nystatin and actidion were added to agar for the protection against fungi growth).

Thirty bacterial strains were isolated at random colonies. Some of their morphological and physiological properties were studied. Most of the bacterial strains were non-sporulate pleomorphic bacteria. Twenty two out of thirty strains studied were able to hydrolyze starch, but only 2-4 to hydrolyze CMC (carboxymethyl cellulose), pectin or tributirin. 


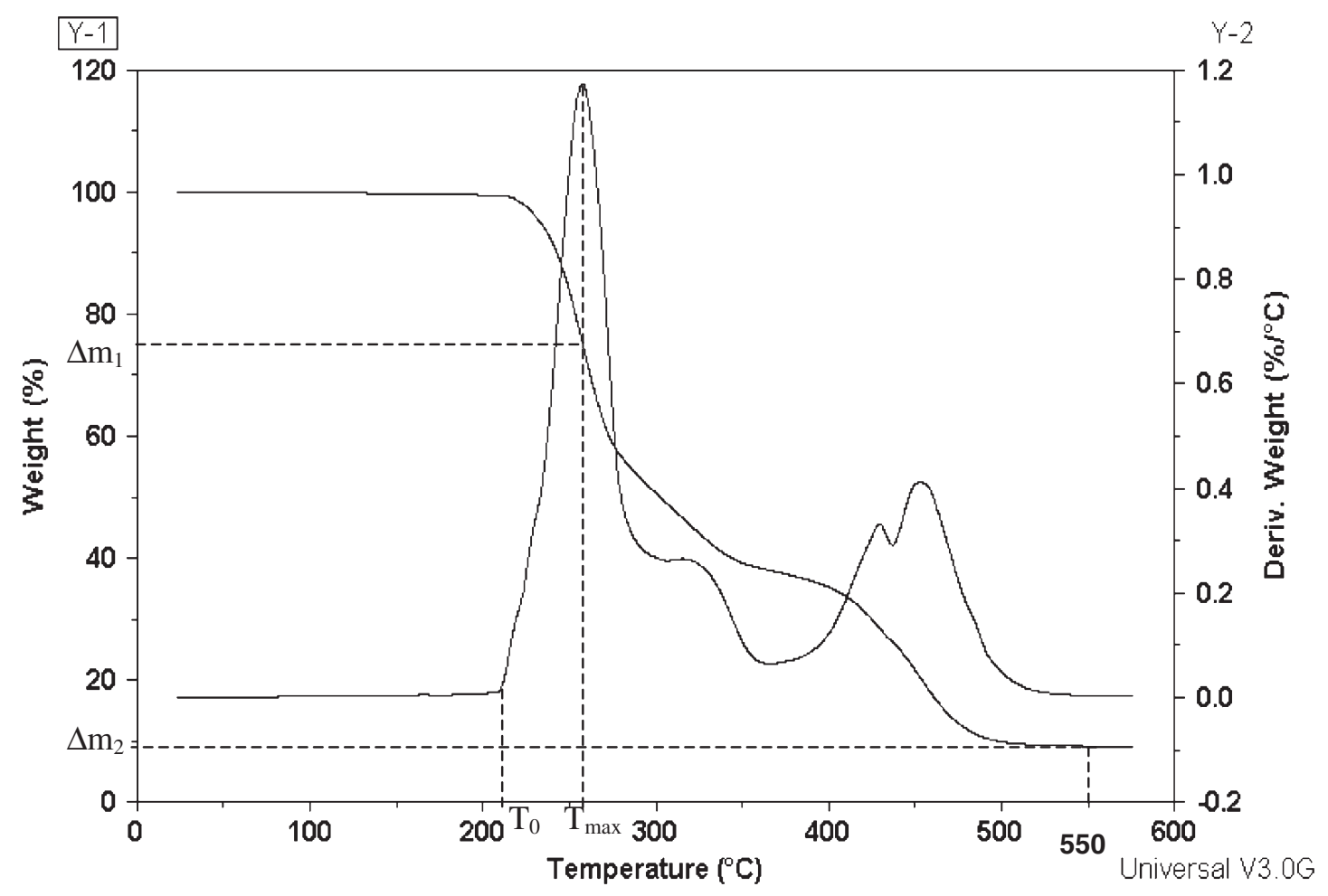

Figure 1. TG and DTG curves of PVC $+10(\mathrm{w} / \mathrm{w})$ cellulose blend obtained under nitrogen atmosphere.

Table II. The mechanical properties of PVC and its composites with cellulose

\begin{tabular}{cccc}
\hline $\begin{array}{c}\text { Amount of cellulose } \\
\text { in blend }(\mathrm{w} / \mathrm{w})\end{array}$ & $\begin{array}{c}\text { Strain at break } \\
\sigma(\mathrm{MPa})\end{array}$ & $\begin{array}{c}\text { Elongation at break } \\
\varepsilon(\%)\end{array}$ & $\begin{array}{c}\text { Young Modulus } \\
E(\mathrm{MPa})\end{array}$ \\
\hline 0 & 41.58 & 6.72 & 1113.6 \\
2 & 42.47 & 5.40 & 1050.6 \\
5 & 35.16 & 6.14 & 1056.4 \\
10 & 34.91 & 4.02 & 1055.0 \\
\hline
\end{tabular}

\section{RESULTS}

\section{The Influence of Cellulose on PVC Properties}

All extruded samples were non-homogenous, nontransparent, white or light-yellow films. The yellow color appeared in pure PVC and sample with a low concentration of cellulose.

The mechanical properties decreased insignificantly as a result of introducing $2-10(\mathrm{w} / \mathrm{w})$ cellulose to PVC composites (Table II). The tensile strain curves of PVC samples with cellulose show brittle behavior. Only PVC itself exhibits a deformation curve characterizing with the neck formation, typical for thermoplastics.

The strain at break $(\sigma)$ decreases by about $15-16 \%$ in PVC + 5-10 (w/w) cellulose, while elongation at break changes by about 9-20\% in relation to the values for PVC samples without cellulose. The Young modulus $(E)$ in modified PVC is lower by $\sim 60 \mathrm{MPa}$, i.e. decreased by about $5 \%$ of the value for unmodified
PVC. The increase of $\sigma$ in the blend PVC $+2(\mathrm{w} / \mathrm{w})$ cellulose, which might suggest some improvement of mechanical resistance of this sample is, however, too small for any reasonable interpretation. The relatively rather small changes in mechanical properties of modified PVC are a result of using aminosilane compatibilizer.

Also the water absorptiveness (WA) of PVC changes only slightly in the presence of small amounts of cellulose. All samples were characterized by WA values of about $1-2 \%$. Generally, some increase of WA was observed at higher contents of cellulose, however, these changes were not higher than $1 \%$. The WA measurements of polymeric compositions are important because the amount of water absorbed by material significantly influences the microbial growth and development of biodegradation. This parameter is also important for packaging materials, as well as for storage of the moisture-sensitive products.

The results of thermogravimetric analysis are presented in Table III and Figures 1 and 2. Taking into 
Table III. Thermal parameters of PVC, cellulose and their blends before and after composting

\begin{tabular}{|c|c|c|c|c|c|c|c|c|c|c|c|c|c|c|c|c|}
\hline \multirow{3}{*}{$\begin{array}{l}\text { Amount of } \\
\text { cellulose } \\
\text { in blend } \\
(\mathrm{w} / \mathrm{w})\end{array}$} & \multicolumn{4}{|c|}{$\Delta m_{1}(\%)$} & \multicolumn{4}{|c|}{$\Delta m_{2}(\%)$} & \multicolumn{4}{|c|}{$T_{0}\left({ }^{\circ} \mathrm{C}\right)$} & \multicolumn{4}{|c|}{$T_{\max }\left({ }^{\circ} \mathrm{C}\right)$} \\
\hline & \multicolumn{4}{|c|}{$\begin{array}{l}\text { Composting time } \\
\text { (months) }\end{array}$} & \multicolumn{4}{|c|}{$\begin{array}{l}\text { Composting time } \\
\text { (months) }\end{array}$} & \multicolumn{4}{|c|}{$\begin{array}{l}\text { Composting time } \\
\text { (months) }\end{array}$} & \multicolumn{4}{|c|}{$\begin{array}{l}\text { Composting time } \\
\text { (months) }\end{array}$} \\
\hline & 0 & 6 & 10 & 14 & 0 & 6 & 10 & 14 & 0 & 6 & 10 & 14 & 0 & 6 & 10 & 14 \\
\hline 0 & 25.1 & 23.3 & 23.7 & 23.1 & 90.83 & 90.80 & 89.90 & 89.31 & 210.9 & 209.4 & 209.4 & 209.4 & 257.9 & 258.8 & 257.9 & 257.9 \\
\hline 2 & 25.4 & 25.2 & 24.6 & 24.1 & 89.60 & 90.06 & 90.11 & 89.10 & 210.4 & 210.4 & 210.4 & 209.4 & 257.9 & 256.9 & 255.9 & 257.9 \\
\hline 5 & 26.3 & 26.5 & 25.8 & 25.8 & 88.00 & 89.66 & 89.63 & 90.31 & 208.4 & 208.4 & 207.5 & 207.5 & 260.8 & 260.8 & 259.8 & 259.8 \\
\hline 10 & 28.2 & 25.6 & 25.8 & 26.3 & 89.87 & 87.50 & 88.11 & 87.70 & 208.4 & 208.4 & 207.5 & 207.5 & 260.8 & 260.8 & 260.8 & 259.8 \\
\hline $100^{*}$ & 45.0 & - & - & - & 93.1 & - & - & - & 291.4 & - & - & - & 331.5 & - & - & - \\
\hline
\end{tabular}

${ }^{*}$ Cellulose was in a form of powder, thus, it was not possible to study its biodegradation in soil.

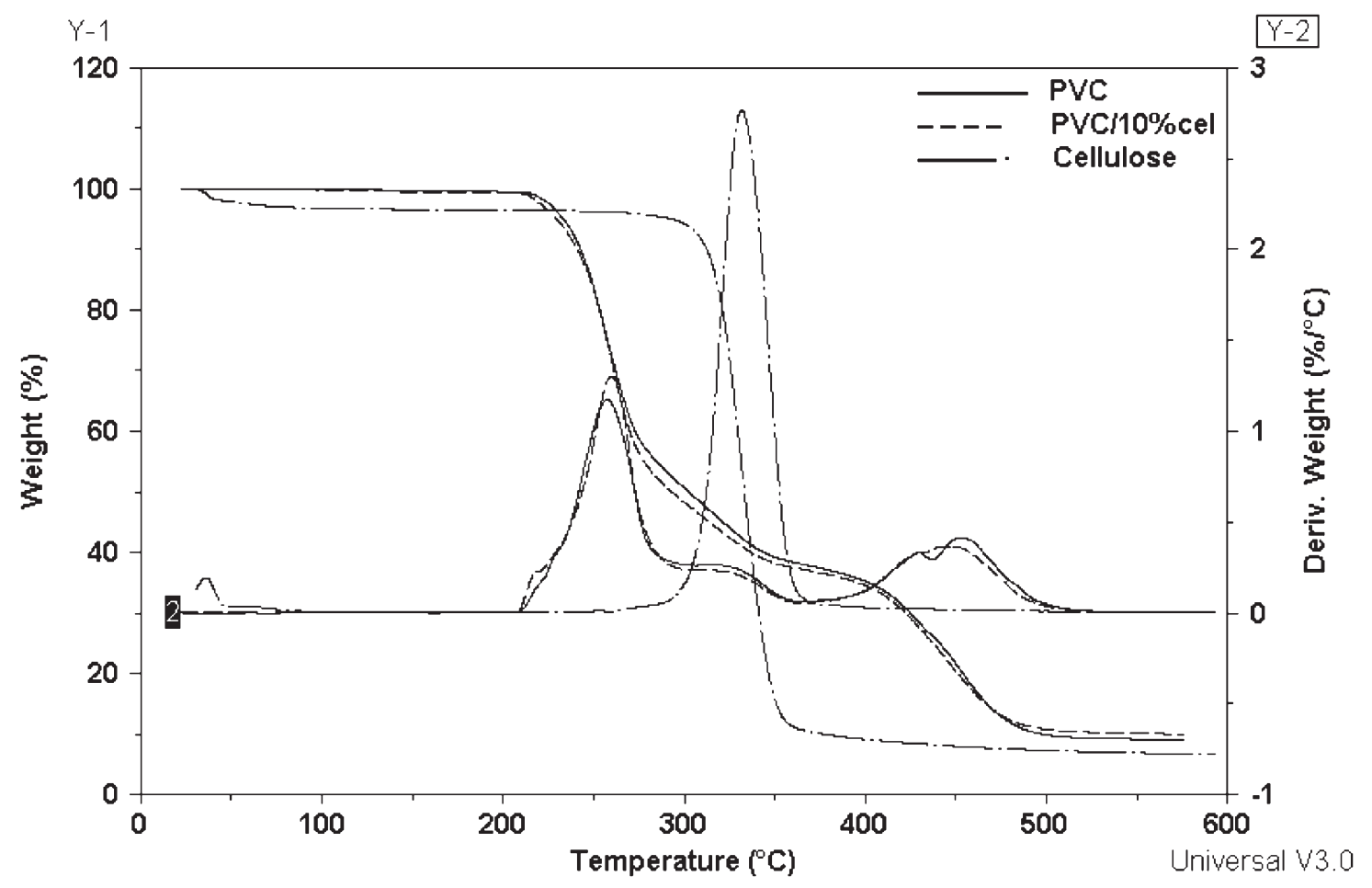

Figure 2. TG and DTG curves of PVC, cellulose and their blend (PVC $+10 \mathrm{w} / \mathrm{w}$ cellulose) before composting.

account the on-set degradation temperature, $T_{0}$, cellulose shows higher thermal stability than other samples studied as its decomposition begins at $290^{\circ} \mathrm{C}$, while in case of PVC and its blends with cellulose this process starts at $\sim 210^{\circ} \mathrm{C}$. The thermolysis of cellulose shows a one-step process ${ }^{16}$ the end of decomposition takes place at the temperature of $400{ }^{\circ} \mathrm{C}$, at which almost the whole sample disappears (weight loss of $\approx 90 \%$ ). The slight decrease of weight (by a few per cent) observed at lower temperatures (from room temp. up to $100{ }^{\circ} \mathrm{C}$ ) indicates that the used cellulose powder contained some loosely bound water, which was removed before degradation.

The thermal degradation of PVC starts at its weak points (i.e., structural defects), which are mainly the units containing allylic chloride, carbonyl groups, or tertiary carbon atoms. ${ }^{17-19}$ Two separate stages can be distinguished during PVC heating. The first one is dehydrochlorination connected with polyenes formation $\left(T_{0}=210^{\circ} \mathrm{C}\right.$ and $\left.T_{\max }=258^{\circ} \mathrm{C}\right)$, while in the second stage $\left(T_{0}=366^{\circ} \mathrm{C}, T_{\max } \approx 440^{\circ} \mathrm{C}\right)$ further degradation of PVC occurs including polyenes decay, main chain scission, and crosslinking. Table III shows only the parameters concerning the first stage, which is decisive for the loss of useful properties.

The TG and DTG curves of PVC $+2,5$ or $10(\mathrm{w} /$ w) cellulose composites are similar to the curves recorded for PVC itself, and only some small shifts have been observed. The detailed changes of thermal parameters obtained from the thermograms of modified PVC, listed in Table III, indicate that 2 (w/w) cellulose addition does not affect thermal parameters of PVC blends. A slight increase of solid residue measured at maximum degradation rate $\left(\Delta m_{1}\right)$ in composites containing 5-10 (w/w) cellulose may suggest that these samples are somehow more stable. Proba- 


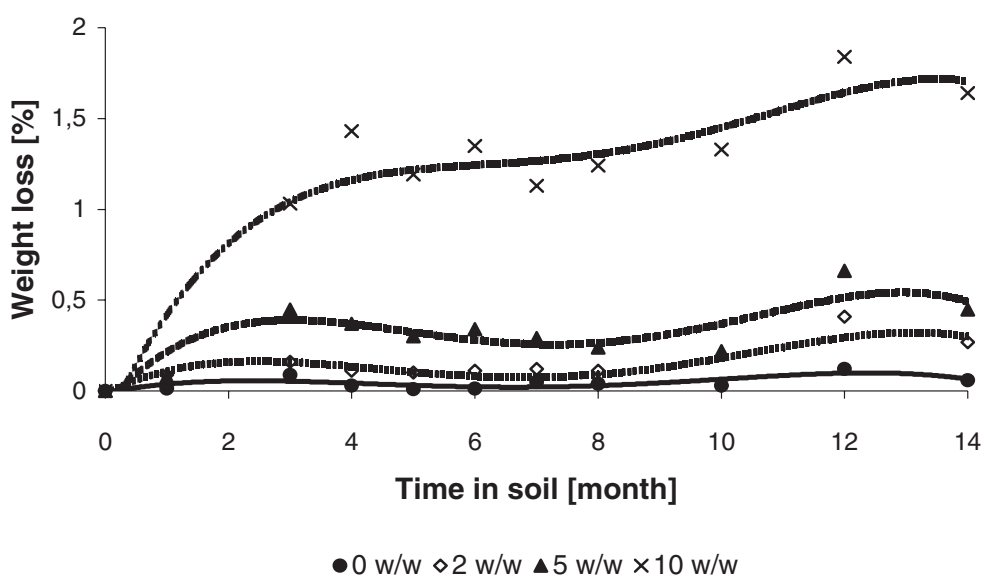

Figure 3. Weight loss of $\mathrm{PVC}$ and its compositions with $2-10(\mathrm{w} / \mathrm{w})$ cellulose versus composting time.

bly, the intermolecular interactions between both polymers facilitate crosslinking processes. The presence of such interactions between cellulose and PVC has recently been suggested in literature. ${ }^{20}$

However, at the end of decomposition, i.e., at $550^{\circ} \mathrm{C}$, the weight loss $\left(\Delta m_{2}\right)$ is almost the same for all samples. The discrepancies of $T_{0}$ and $T_{\max }$ temperatures are negligible $\left(\sim 2{ }^{\circ} \mathrm{C}-\right.$ not exceeding the experimental error).

Effect of Composting on the Properties of PVC Modified by Cellulose

The changes of weight in biodegraded samples are presented in Figure 3. During the first month of composting, all changes were insignificant. After applying a longer time, the differences between PVC and its blends with cellulose were clearly visible. The weight loss was higher in samples containing a larger amount of cellulose, but the changes were still rather slight even after 14 months of composting. It can be concluded that only $50 \%$ portion of cellulose present in PVC composite undergoes disintegration during oneyear composting. It is also possible that other additives can undergo biodegradation, however, their total amount in the composites does not exceed $8 \%$ in relation to PVC.

The visual observations of sample surface (Figure 4) confirm the expectations that biodegradation occurs only in the part of natural polymer. The composted specimens show a visible erosion of their surface mainly around cellulose domains.

Water absorptiveness (WA) slowly increases in all samples during composting (Figure 5). It can be caused by erosion taking place in samples, which become more porous. There are not any significant differences in the tangent of plotted lines shown in Figure 5, which indicate that the effect of biodegradation on this measured property depends rather slightly on sample composition. Although the increase of WA

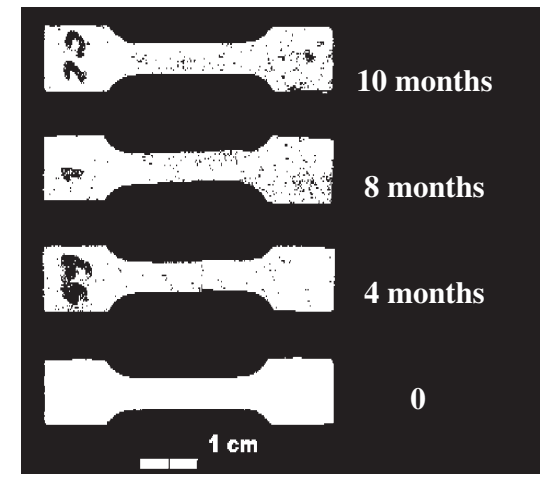

Figure 4. Surface changes in PVC $+10(w / w)$ cellulose before (0) and after 4, 8 and 10 months of soil composting.

absolute value is low, the percentage changes after 12 months of composting are considerable, namely amounting to $48-55 \%$.

The ATR-FT IR spectra of composted blends show some small changes in the following ranges: 1000$1100 \mathrm{~cm}^{-1} \quad$ (C-O-C), $1500-1800 \mathrm{~cm}^{-1}$ (carbonyl groups and unsaturated bonds), and $3000-3500 \mathrm{~cm}^{-1}$ (hydroxyl groups) (Figure 6). It is an evidence of reactions occurring in macromolecules at the samples' surface (mainly the decomposition of cellulose connected with breaking of $\mathrm{C}-\mathrm{O}$ linkages and abstraction of $\mathrm{OH}$ groups, as well as formation of carbonyl groups resulting from the oxidation and simultaneous destruction of Ergoterm ES). The interpretation of FT IR results was facilitated by comparing the spectra of PVC + cellulose blends with the spectra of pure components. The spectrum of blend after 10 months composting (Figure 6C) differs from others-clear band at $1020 \mathrm{~cm}^{-1}$ is seen. It is assigned to complex $\mathrm{C}-\mathrm{O}$ and $\mathrm{O}-\mathrm{H}$ vibrations from cellulose. ${ }^{16}$ This is an evidence of non-homogeneity of samples studied. In observed case, IR beam found such surface point, where cellulose was less covered by PVC.

The relatively insignificant changes observed in the 


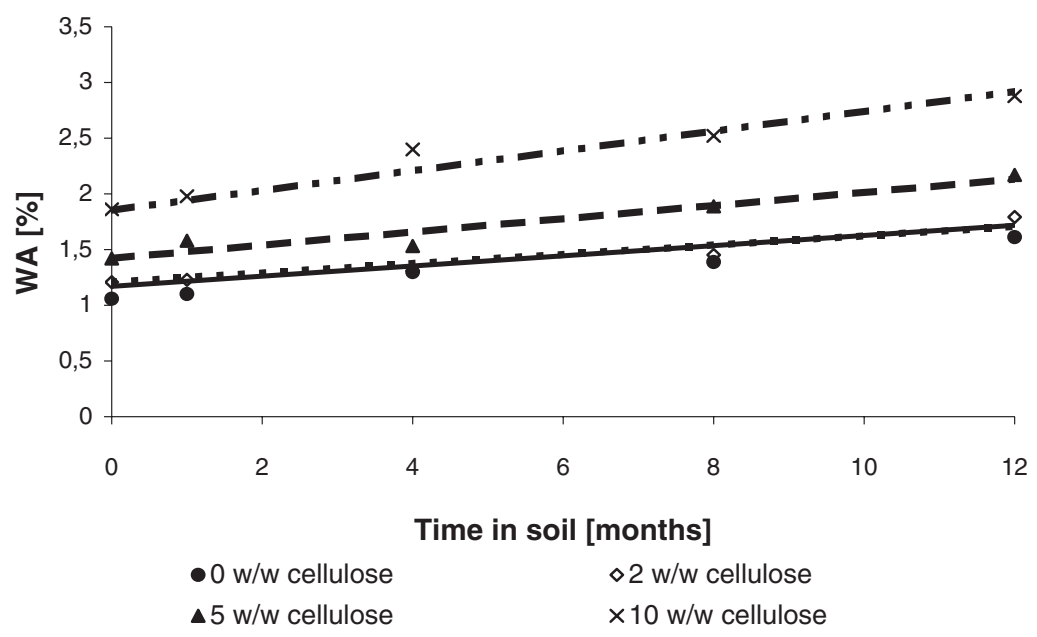

Figure 5. Water absorptiveness (WA, \%) of PVC and it compositions with $2-10(\mathrm{w} / \mathrm{w})$ cellulose versus composting time.

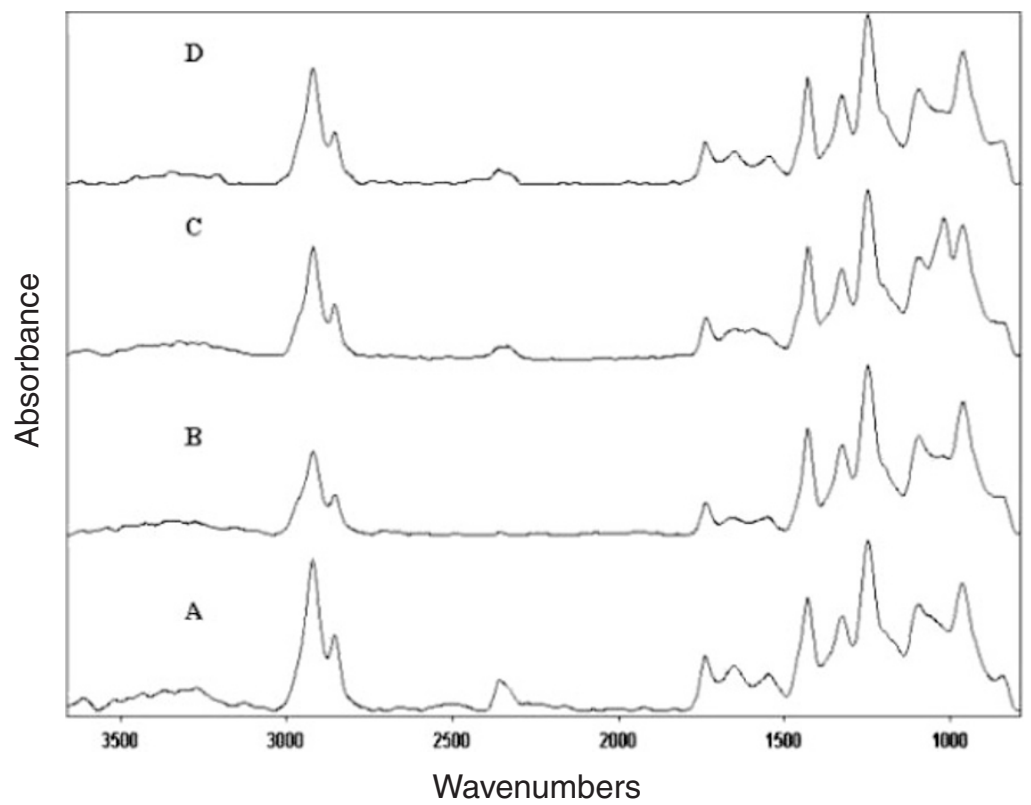

Figure 6. ATR-FT IR spectra of PVC $+10(w / w)$ cellulose after $0(A), 6(B), 10(C), 14(D)$ months of soil composting.

spectra of composted samples of PVC blends were probably caused by the migration of compounds added for proper extrusion process. Changes of PVC spectra in the region of $1500-1700 \mathrm{~cm}^{-1}$, which are similar to changes in the spectra of PVC doped with cellulose, indicate the occurrence of dehydrochlorination process. Standard UV-vis absorption spectroscopy, which is normally useful in tests monitoring the formation of polyenes in PVC during degradation, could not to be used in case of our samples because they were nontransparent.

The mechanical properties of composted samples decrease gradually (Figures 7 and 8). After biodegradation, the stress at break drops in all samples and the observed changes are highest at the first interval of process ( $2-4$ months). Composting for a longer time causes only small irregular changes.

In PVC itself, i.e., without cellulose, the decrease of stress at break was also observed during biodegradation, although these changes were smaller than those in blends with cellulose. It may suggest that even in PVC itself (without cellulose) some bioprocesses running at a low efficiency can take place. It is confirmed by small values of weight loss found in samples of PVC and its blends (Figure 3). Probably, the biodegradation of additives introduced for facilitating extrusion may also be responsible for those small weight losses and deterioration of mechanical properties in PVC blends at the beginning of composting.

The same conclusion can also be drawn on the basis of elongation at break calculated from tensile tests (Figure 8). After biodegradation, a similar trend of 


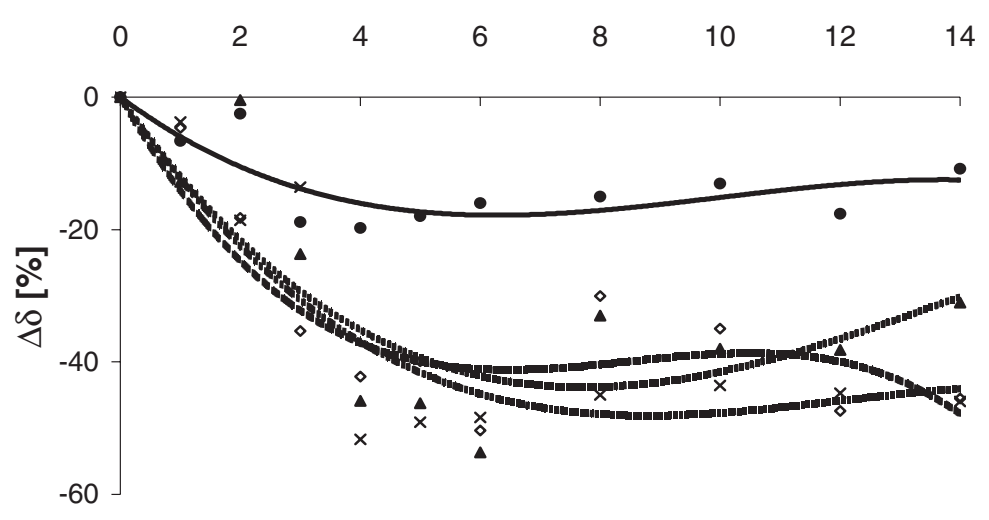

Time in soil [months]

$\begin{array}{ll}\bullet 0 \mathrm{w} / \mathrm{w} \text { cellulose } & \diamond 2 \mathrm{w} / \mathrm{w} \text { cellulose } \\ \triangle 5 \mathrm{w} / \mathrm{w} \text { cellulose } & \times 10 \mathrm{w} / \mathrm{w} \text { cellulose }\end{array}$

Figure 7. Relative changes of strain at break in PVC and PVC $+2-10(w / w)$ cellulose versus composting time.

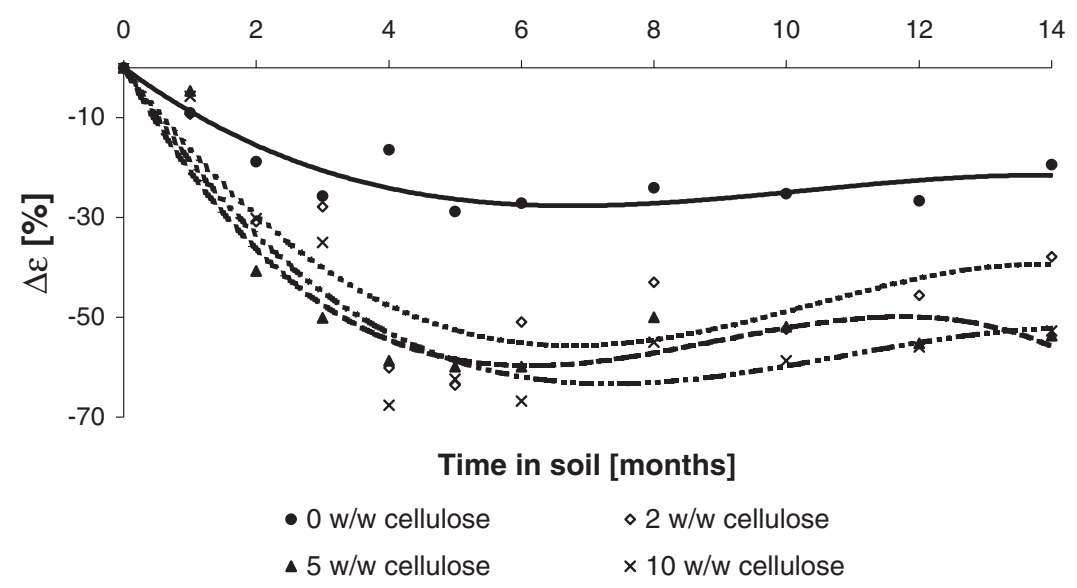

Figure 8. Relative changes of elongation at break in PVC and PVC $+(2-10 \mathrm{w} / \mathrm{w})$ cellulose versus biodegradation time.

changes concerning tensile strength was found. The ultimate elongation after 14 months of composting decreased in pure PVC by about $20 \%$, whereas in the modified samples-by about $40-60 \%$. The ultimate elongation after 14 months of composting decreased in pure PVC by about $20 \%$, whereas in the modified samples-by about $40-60 \%$. Moreover, on the base of thermogravimetric analysis, it can be concluded that thermal stability of composted samples changed insignificantly (Table III and Figure 9).

\section{DISCUSSION}

We have found rather an insignificant effect of cellulose on PVC properties. Only the addition of cellulose at $10(\mathrm{w} / \mathrm{w})$ ratio caused somewhat higher changes in the mechanical properties, thermal resistance and water absorptiveness of PVC blends.

Although cellulose is a biodegradable polymer, its content of 2-10\% does not induce any rapid biodegradation of PVC composites. It is generally assumed that materials classified as readily biodegradable should be characterized by $60-90 \%$ conversion index of biodegradation at the end of testing period (not longer than $180 \mathrm{~d}) .{ }^{1,8}$

Biodegradation of polymers depends on chemical structure of macromolecules, composition, amount and types of microorganisms colonies, humidity of environment, $\mathrm{pH}$, oxygen concentration, and temperature. The presence of other additives containing active groups can additionally accelerate or hamper biodecomposition of plastics. The proper ordering of macromolecules (crystallinity) and physical state of polymer are also important factors influencing the degradation processes, which occur mainly in the amorphous part of polymer. Access of degrading agents to the compact crystalline phase of high density is much more difficult.

Microorganisms produce enzymes, which can attack macromolecules. Their effectiveness depends on the amount of reactive centers and functional groups in macrochains. Generally, the lower molecu- 


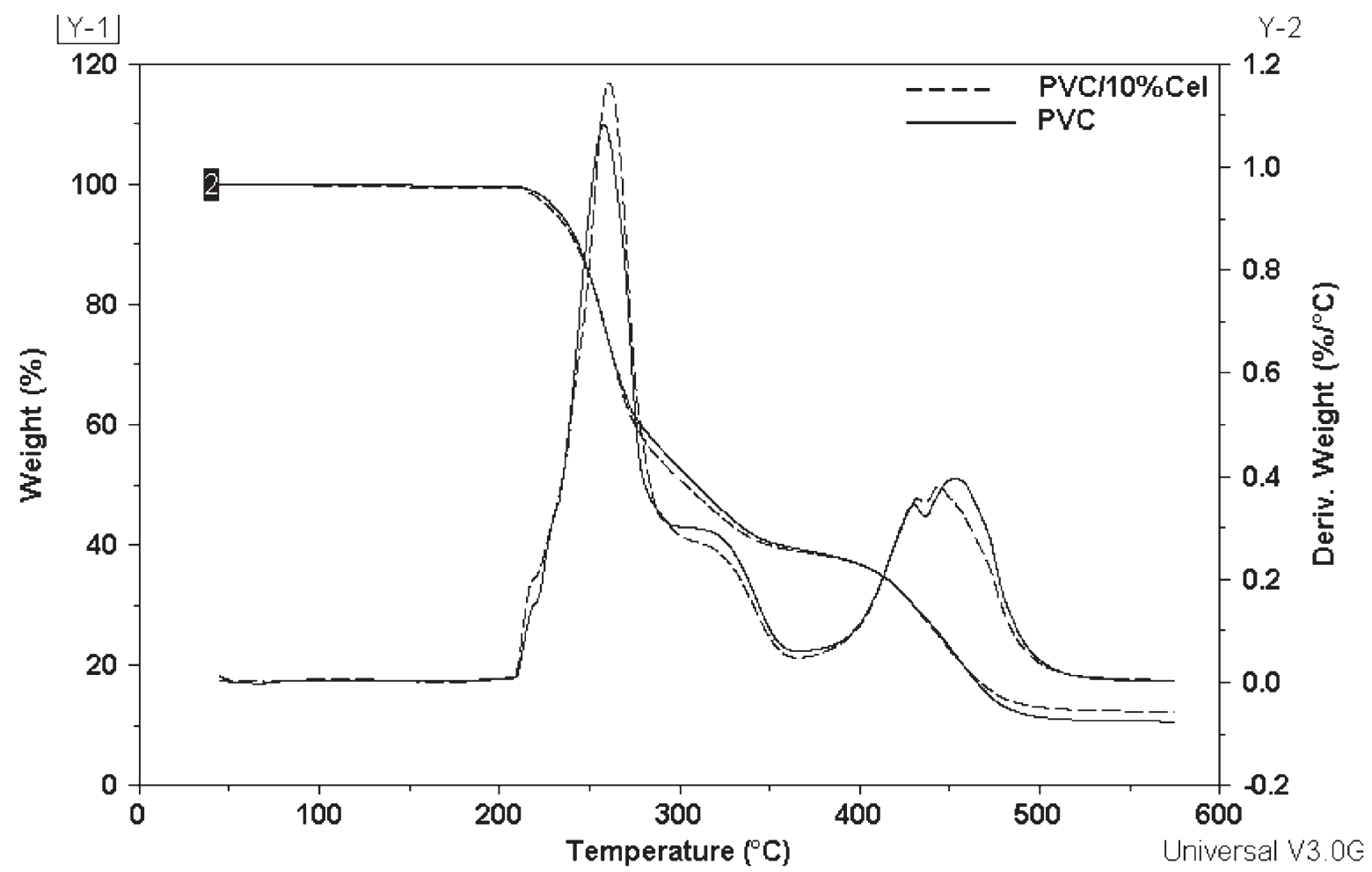

Figure 9. Thermograms of PVC and PVC $+10(w / w)$ cellulose blend after 14 months of composting.

lar weight (shorter chains), the higher concentration of end groups, thus, also the higher yield of biodegradation. The presence of water is necessary for proper growth of microorganisms; water also participates in hydrolysis of some macromolecules; oxygen (as well as ozone) leads to oxidation of macromolecules. The oxidized groups facilitate further microbial attack, moreover, they are also sensitive to photodegradation (carbonyl groups undergo the Norrish Type I and II reactions).

The kinetics of enzymatic reactions, thus also the biodegradation kinetics, depend on the concentration and activity of enzymes, $\mathrm{pH}$, temperature, presence of oxygen, activators and inhibitors. Various cultures of microorganisms characterize with different requirements for their optimal growth. The highest growth rate of bacteria is observed in neutral or slightly alkaline environment, while fungi develop in slightly acidic conditions of environment. Bacteria prefer the conditions of higher humidity ( $>30 \%$ ), while fungi tolerate also lower content of water. ${ }^{13,14,21}$

Our blends consisted of PVC, which is an amorphous polymer with glass transition of about $80^{\circ} \mathrm{C}$. It is mainly built of the head-to-tail structures (content of head-to-head structure is only $\sim 0.6 \%$ in commercial PVC). Cellulose, a natural component, is built of D-glucose rings linked through carbon atoms 1 and 4 as $\beta$ linkages. It exists in two forms: $\alpha$ and $\beta$, in which $\mathrm{OH}$ and $\mathrm{CH}_{2} \mathrm{OH}$ substituents differ in their positions (equatorial or axial). This natural polymer is characterized by a high degree of crystallinity and high amount of intramolecular and intermolecular hydrogen bonding.

Mixing of both polymers at a high temperature (during extrusion) destroys the crystalline order in cellulose, but simultaneously the processed composition can be partially crosslinked. Both mentioned factors characterize with opposite effects: lack of crystallinity should facilitate biodecomposition, whereas crosslinking hampers it.

The destruction of crystallinity may also lead to some mutual interactions between PVC and cellulose in blends, which are possible as both polymers contain electronegative atoms in their repeating units (oxygen and chlorine atoms in cellulose and PVC, respectively). Such interactions can enhance the resistance and durability of said composites. According to the recently published results, the hydrogen bonds or specific dipole-dipole interactions in polymer blends improve their photostability. ${ }^{22,23}$

The biodegradation of cellulose is mainly caused by three types of enzymes: endoglucanases (attacking the amorphous part of cellulose chain), exoglucanases (degradating the crystalline phase of cellulose to celobiose), and $\beta$-glucosidases (hydrolysing celobiose to glucose) ${ }^{24}$ The absorption of enzymes by cellulose, which is necessary for biodegradation, depends on the surface active centres. ${ }^{25}$ The ezymatic activity of numerous microorganisms has been studied in detail. $^{26-29}$ The microbial mechanism of biodegradation, 
including also the chemical reactions occurring in cellulose in natural environment, have been described elsewhere. ${ }^{30}$

The microbiological analysis of soil used in our studies showed that its $\mathrm{pH}$ slightly decreases during the composting experiment, which is a result of PVC dehydrochlorination. It may facilitate the fungi growth. On the other hand, however, acidification is rather unfavorable to the growth of some bacteria, and it may also cause the deactivation of enzymes in some cases. Thus, it seems that the soil used by us did not contain a sufficient amount of cellulolytic bacteria. Also in other natural environments, the enzymes causing biodegradation of cellulose are less prevalent than, for example, the enzymes decomposing starch. ${ }^{21}$

Probably, the observed very slow biodegradation was also caused by the loose structure of soil and its low water absorbability. As the humidity of soil was decreasing quite rapidly, it was necessary to supplement water every day.

Observations of the surface of composted samples lead to the conclusion that biodegradation occurs mainly in cellulose domains. Our samples contained a relatively low amount of cellulose-its higher contents should increase biodegradability, but simultaneously the mechanical properties will be deteriorated.

According to the findings by Sawada, ${ }^{31}$ the negative results in laboratory biodegradation tests do not necessarily mean that plastics will not degrade in certain specific natural conditions.

In natural environment, several factors act simultaneously on polymers and there occurs a complex mechanism of degradation. For example, inorganic or organic impurities (acting in chemical reactions as catalysts, initiators or sensitizers), ozone, UV-radiation, elevated temperature (especially in summer, in tropical zones) can significantly influence the course of biodegradation.

Thus, the biodegradation of PVC blends modified by means of small amounts of cellulose is a multistep, slow, but continuous process. Basing on the above mentioned findings, one can expect and conclude that after the decay of cellulose, the process of environmental decomposition will be continued because various active agents will diffuse deeper and deeper into the material. In case of lack of a natural polymer, also PVC itself (partially degraded and oxidized) can be a source of carbon for microorganisms needing it for their metabolic processes.

\section{CONCLUSIONS}

The addition of small amounts of cellulose (2-10 w/w) to PVC affects insignificantly the physical prop- erties and biodegradability of this plastic. The mechanical properties of composites containing cellulose are slightly lower that those of unmodified PVC. Also the index of water absorptiveness increases insignificantly in PVC doped with cellulose. The thermal stability practically does not change after the addition of cellulose to PVC blends and also after composting them for 1 year.

It has been found that only about $50 \%$ portion of added cellulose undergoes decomposition during long-term composting of PVC + cellulose blends. Small changes noticed in FT IR-ATR spectra as well as the visual observations indicate that some chemical reactions take place on the sample surface. The weight loss is a little higher in samples with $10(\mathrm{w} / \mathrm{w})$ content of cellulose than that appeared in other composted samples. It can be concluded that a small amount of cellulose might be used as a filler for PVC blends.

The reason of relative bio-stability of PVC $+2-10$ $(\mathrm{w} / \mathrm{w})$ cellulose blends, higher than expected, is probably the reaction of thermal crosslinking during extrusion, which impedes the access of microorganisms to the internal parts of specimen. Such a relative biostability may also be caused by molecular interactions between both polymers, which reinforce the composite structure.

There can be proposed the application of PVC blends modified with cellulose as a construction material of medium durability. The idea of using polymerwood composites (wood in a form of wood-powder containing about $50 \%$ pure cellulose) as a material for garden furniture has recently been presented. ${ }^{32}$

Acknowledgment. The authors thank Prof. Hanna Dahm and Dr. Aleksandra Pokojska-Burdziej (Department of Microbiology, Faculty of Biology and Earth Sciences, Nicolaus Copernicus University, Toruń, Poland) for cooperation and assistance in the microbiological analysis.

\section{REFERENCES}

1. J. D. Hamilton and R. Sutcliffe, "Ecological Assessment of Polymers," Van Nostrand Reinhold, New York, N.Y., 1997.

2. G. Scott and D. Gilead, "Degradable Polymers. Principles and Applications," Chapman and Hall, London, U.K., 1995.

3. J. Guillet, Macromol. Symp., 123, 209 (1997).

4. S. H. Hamid, Ed., "Handbook of Polymer Degradation," 2nd ed., Marcel Dekker, New York, N.Y., 2000.

5. A. J. Domb, J. Kost, and D. M. Wiseman, Ed., "Handbook of Biodegradable Polymers," Harwood Academic Publishers, Amsterdam, 1997.

6. M. Mucha, "Polimery a Ekologia (Polymers and Ecology)," Wydawnictwo Politechniki Łódzkiej, Lodz, 2002.

7. Standard Guide for Assessing the Compostability of Environmentally Degradable Plastics, ASTM, D 6002-96. 
8. Standard Test Method for Determining Aerobic Biodegradation of Plastic Materials under Controlled Composting Conditions, ASTM, D 5338-98.

9. Standard Specification for Compostable Plastics, ASTM, D 6400-99.

10. W. Szlezyngier, “Tworzywa Sztuczne," Rzeszów, 2003, vol. 3.

11. Polish norm: PN-81//C-89034.

12. Polish norm: PN-81//C-89032.

13. A. Chmiel, "Biotechnologia Podstawy Mikrobiologiczne I Biochemiczne (Biotechnology Microbiological and Biochemical Basis)," PWN, Warsaw, 1998.

14. A. Różalski, "Ćwiczenia Z Mikrobiologii Ogólnej (Exercises in General Microbiology)," Wydawnictwo Uniwersytetu Łódzkiego, Lodz, 1996.

15. H. G. Schlegel, "Mikrobiologia Ogólna (General Microbiology)," PWN, Warsaw, 1996.

16. S. Soares, G. Camino, and S. Levchik, Polym. Degrad. Stab., 49, 275 (1995).

17. J. Wypych, "Polyvinyl Chloride Degradation," Elsevier, Amsterdam, 1985.

18. K. S. Minsker, S. V. Kolesov, and G. E. Zaikov, "Degradation and Stabilization of Vinyl Chloride Polymers-based Polymers," Pergamon, New York, N.Y., 1988.

19. W. H. Starnes, Jr., Prog. Polym. Sci., 27, 2133 (2002).
20. Y. Matsuzawa, M. Ayabe, and J. Nishino, Polym. Degrad. Stab., 71, 435 (2001).

21. W. J. H. Kunicki-Goldfinger, "Życie Bakterii (Bacteria Life)," PWN, Warsaw, 1998.

22. H. Kaczmarek, A. Szalla, and A. Kamińska, Polymer, 42, 6057 (2001).

23. H. Kaczmarek, R. Drąg, M. Świątek, and D. Ołdak, Surf. Sci., 507, 877 (2002).

24. M. Itävaara, M. Siika-aho, and L. Viikari, J. Environ. Polym. Degrad., 7, 67 (1999).

25. L. Stryjer, "Biochemia (Biochemistry)," 4th ed., PWN, Warsaw, 1997.

26. H. Dahm and E. Strzelczyk, Symbiosis, 18, 233 (1995).

27. H. Dahm, E. Strzelczyk, and M. Mańka, Phytopathol. Pol., 13, 19 (1995).

28. H. Dahm and E. Strzelczyk, Acta Mycol., 31, 181 (1996).

29. H. Dahm, E. Strzelczyk, R. Pachlewski, and H. Różycki, Pedobiologia, 43, 193 (1999).

30. M. M. Askarieh, A. V. Chambers, F. B. D. Daniel, P. L. FitzGerald, G. J. Holtom, N. J. Pilkington, and J. H. Rees, Waste Manage., 20, 93 (2000).

31. H. Sawada, Polym. Degrad. Stab., 59, 365 (1998).

32. M. Gnatowski, C. Mah, M. Manning, and K. Morris, Proceedings of World Polymer Congress, IUPAC, MACRO, Paris, 2004. 